\title{
Parents' Experiences and Sexual Topics Discussed with Adolescents in the Accra Metropolis, Ghana: A Qualitative Study
}

\author{
Elizabeth AKu Baku $\mathbb{D}^{0},{ }^{1}$ Isaac Agbemafle $\mathbb{D}^{\mathrm{D}}{ }^{2}$ \\ Agnes Millicent Kotoh $\mathbb{D}^{3}$, and Richard M. K. Adanu ${ }^{4}$ \\ ${ }^{1}$ School of Nursing and Midwifery, University of Health and Allied Sciences, Ho, Volta Region, Ghana \\ ${ }^{2}$ Department of Family and Community Health, School of Public Health, University of Health and Allied Sciences, Ho, \\ Volta Region, Ghana \\ ${ }^{3}$ Department of Population, Family and Reproductive Health, School of Public Health, University of Ghana, Legon, \\ Greater Accra Region, Accra, Ghana \\ ${ }^{4}$ Office of the Dean, School of Public Health, University of Ghana, Legon, Greater Accra Region, Accra, Ghana \\ Correspondence should be addressed to Elizabeth AKu Baku; ebkpodotsi@uhas.edu.gh
}

Received 30 April 2018; Revised 8 August 2018; Accepted 4 October 2018; Published 1 November 2018

Academic Editor: Carol J. Burns

Copyright (C) 2018 Elizabeth AKu Baku et al. This is an open access article distributed under the Creative Commons Attribution License, which permits unrestricted use, distribution, and reproduction in any medium, provided the original work is properly cited.

Background. Traditionally, discussion about sexuality is subdued in proverbs and is earmarked for adults. However, adolescents also need information about their sexuality to make informed choices regarding sexual behaviours. This study, therefore, seeks to explore the experiences of parents discussing sexuality topics with adolescents in the Accra Metropolis, Ghana. Methods. This was a qualitative study that used focus group discussions (FGDs) and in-depth interviews (IDIs) to assess parents' experiences in discussing sexuality topics with adolescents. The FGDs, consisting of 8-12 parents each, were conducted for one "all fathers", then another "all mothers", and finally "fathers and mothers" groups. Parents who were not part of the FGDs were engaged in IDIs. The data was transcribed and analyzed manually. Results. Most of the parent-adolescent sexual discussions were based on physical changes, personal hygiene, abstinence, abortion, and saying "no" to forced sex. Parents discussed sexuality issues with adolescents to prevent them from premarital sex, pregnancy, and sexually transmitted infections. Parents sourced their knowledge about sexuality from books, television, radio, and personal experiences. Parents always seize opportunities such as television scenes to discuss sexual topics with their children. Although some parents expressed some level of comfort discussing sexual topics with adolescents, many still had difficulties explaining some terminologies related to sex. Preferentially, parents were protective of their girls than the boys when discussing issues on sexuality. Most parents received no sexuality education from their parents but a few reminisced precautionary advices on sex. Parents believed training on sexuality issues will help them to better discuss sexual topics with adolescents. Conclusions. Ghanaian parents preferentially discuss sex with their daughters as a protective tool against irresponsible sexual behaviours. Parents still have challenges discussing adolescent sexuality topics; hence equipping parents to effectively discuss such sensitive topics will improve adolescent reproductive health and sexual behaviour.

\section{Introduction}

Adolescence is a period of risk taking, particularly on sex, but many adolescents are not educated about their sexual and reproductive health issues by their parents (Arnett, 2003) [1]. Lack of education on sexual and reproductive health for adolescents may lead to increased risk of sexually transmitted infections (STIs), unintended pregnancy, and other health problems [2]. Sedgh and Hussain noted that even though the importance of sexuality education is accepted, the intervention is opposed in many African countries, including Ghana, probably because of cultural beliefs and norms [3]. This stems from the fact that early introduction to information about sexuality and reproductive health could be seen as detrimental to adolescents than helping them to overcome sexual and reproductive health risks that they face 
in growing up. In Kenya, the main barrier to meaningful sex education between mothers and their daughters was taboos that prevent parents from discussing sex with their children [4]. In the Kenya study, most mothers had no sex education either from their parents or other family members and hence could not talk about sex to their own daughters. Similarly, parents in three cities in different regions of the United States complained that their parents never talked to them about sex; therefore it was difficult for them to know how to talk about sex to their own children [5]. Beyer reported that sex is still not discussed in certain localities in South Africa because adolescents in those localities were perceived as a high-risk group that could become curious about their sexual desires $[6]$.

Although censored, the 2014 Demographic and Health Survey report indicated that about $42.7 \%$ of Ghanaian girls and $26.6 \%$ of boys become sexually active in their teens [7]. A 2004 national representative survey in Ghana indicated that nearly $75 \%$ of sexually active adolescent girls and $33 \%$ of sexually active boys reported receiving money or gifts in exchange for sex [8]. Indeed, this is a usual component of "boy-girl-friend" relationships in Ghana and other African countries. Irrespective of the risks associated with being an adolescent, talking about sex and sexual activities is not openly encouraged in Africa probably because sex is considered a sacred adult affair that is enshrined in secrecy. A negative effect arising out of secrecy could be incidence of teenage pregnancy that was recorded in many African countries including Ghana. For example in 2014 Ghana recorded teenage pregnancy rate of $11.8 \%$ [9] as compared to other African countries like Nigeria 23\% [10], Kenya 18\% [11], and South Africa 13.9\% [12].

In Ghana, cultural taboos prevented education of adolescents on sexuality. Among the Akans, for instance it was a taboo to talk about sexual issues with a child because they believed that the child could be "spoilt". Even if the child wanted to find out certain things about sex, they would tell the child that he/she was not matured enough to know about such issues. Due to the taboos associated with sexuality education, some parts of the body could not be mentioned because it was considered a taboo to do so. For that matter, they expressed such things using euphemisms. For example, they prefer to call the penis "manhood". Some sexual discussions only took place with the girl after menarche. No education is given to boys on their sexuality [13].

Ghanaian culture considers sexuality as sacred; that is, it is something that should not be discussed with children and adolescents. In Ghana, teaching of sex education to children is generally seen as introducing them to early sexual intercourse and, subsequently, pregnancies. The understanding and tolerance for sex education among Ghanaian parents are nonexistent. Culture, thus, accounts for this intolerance for sex education[14].

However, there is some evidence of parent-adolescent sexuality discussion in some Ghanaian homes. A nationally representative data from Ghana showed adolescent communication with family and nonfamily members [15]. Traditionally, adolescents in Africa are rebuked for questioning their parents, particularly on issues concerning sex, and they would be described as "spoilt children". Brocato and Dwamena-Aboagye documented that Ghanaian children, especially girls, are brought up with strict discipline and fear, making them timid to ask very sensitive questions on adolescent sexuality issues [16].

The Ghana Education Service has approved a crosscurricular method, in which some subjects related to sexual and reproductive health (SRH) have been included in specified school topics [17]. Basic SRH education topics are introduced in the fourth year of primary school, a level at which all subjects, including those that cover SRH topics, are required. However, in senior high school, the topics are included into two core, compulsory subjects (social studies and integrated science) and two elective subjects (biology and management in living). There are also two main cocurricular programs that offer additional activities outside of the regular curriculum, either during or after school: The School Health Education Programme (SHEP) and the HIV alert program. The goal of SHEP is to guide children in school to acquire the knowledge, skills and attitudes needed to achieve lifelong health [18]. The HIV alert programme, on the other hand, stresses the prevention of HIV infection and the significance of interrelated issues, such as chastity and abstinence. Both programs operate in all schools in Ghana and they target students in primary and junior high schools in particular. These are also offered in senior high schools with support from the Ministry of Health and the Ghana Health Service. The programme also exists in colleges of education as part of the preservice training for teachers who will teach this subject at the primary and junior high school levels [18].

In Ghana, religion and morality are considered as bed associates and study shows that religious teaching in Ghana from all the three major religious groups-Christianity, Islam, and traditional religions-forbids sex outside the background of marriage and, therefore, views it as a sin [19]. Religion has, therefore, been found to exercise the greatest effect on sexual socialization in Ghana than the state and society [19]. The moral structure religion produces seemed strong to the extent that parents saw it as substitute to the traditional system. When they could not exercise any meaningful influence on regulating their adolescents' sexual behaviours, they switch to religion for help [20]. The switch towards religion as a regulating moral mechanism over adolescents' sexual behaviour is validated on the perceived benefits from the moral system. Parents perceived religion as playing two major positive roles in regulating adolescent sexual behaviours. The first was the inhibition role. This is the view that religion values discourage children from certain immoral acts like sex. Secondly, religion was perceived to play a facilitative role. In this role, religious values, principles, ideals, and perhaps beliefs teach adolescents to make good choices. The role is best instigated by religious leaders in churches who basically become counsellors for adolescents. The talk therapy that is observed is reflective of religious directing the choice of adolescent behaviours [20].

In Africa, parent-adolescent communication on sexuality has turned sexuality discussion into forbidden subject for fear that adolescents may become curious about their sexual desires. On the contrary, there is considerable evidence 
that parent-adolescent sexuality communication is linked to reduction in risky adolescent sexual behaviours and delays in initiation of sexual intercourse $[21,22]$. Success of parentadolescent sexuality communication depends on parents as gatekeepers of sexuality information. At home, parents define content of adolescent sexuality discussion but there may be gaps between what they perceive that adolescents need and what adolescents themselves really need [23]. This creates conflict and leads to prevention of communication as many parents and adolescents do not have the ability to engage in active sexuality discussions. This present study, therefore, seeks to examine parents' opinions in relation to discussions with their adolescents about sexuality.

\section{Materials and Methods}

2.1. Study Design and Setting. A qualitative exploratory study design was used to explore the experiences of parents discussing topics on sex with their adolescent children in the Accra Metropolis, Ghana. The study has its research setting at the Osu Klottey and Ablekuma South submetropolises in the Accra Metropolis. The Accra Metropolis has 11 submetropolises, and the study was conducted in these two submetropolises because they are geographically far apart and very diverse. The Osu Klottey submetropolis is one of the oldest $\mathrm{Ga}$ communities along the coast in Accra and its inhabitants are mainly fishermen and fishmongers. Ablekuma South is a newly created submetropolis and it is cosmopolitan in nature.

2.2. Selection of Participants. Parent, defined as either the biological father or mother of the adolescent, was selected for the study if his/her adolescent child attends a public junior high school and has been living in one of the two areas for at least one year. The parents were recruited through their adolescent children in school using the simple balloting technique. A parent whose adolescent child picks "yes" from the ballot papers was given a letter inviting his/her parent to be part of the study. Parents who indicated their willingness to participate in the study signed informed consent forms and were recruited. The age range of the parents was between 25 and 55 years. Forty-four parents ( 6 teachers, 3 nurses, 2 mechanics, 1 pastor, 11 traders, 1 administrative officer, 2 record officers, 4 bankers, 12 artisans, and 2 hair dressers) were selected for the study. All the parents who were invited to take part in the study participated except one parent who travelled at the time of the study.

2.3. Data Collection. Focus group discussions (FGDs) and in-depth interviews (IDIs) were used to collect the data for the study. Four FGDs were held: 2 mothers' groups, 1 fathers' group, and 1 mixed group (both mothers and fathers). The IDIs were held with 6 mothers and 4 fathers (2 teachers, 1 nurse, 1 mechanic, 4 traders, 1 record officer, and 1 administrative officer). The FGDs were used because of the group dynamics that stimulate discussions, generate ideas, and provide the opportunity to explore sensitive issues or pursue a topic in greater depth. This produces results that are peculiar to the mix of people and provides more insights into the subject of study. IDIs have the advantage of avoiding too much prejudgment, if the questions asked are not restrictive and can elicit information that reflects the interviewees' views and beliefs about an issue [24].

The in-depth interviews (IDIs) were conducted with parents in the comfort of their homes. The focus group discussions were held in a classroom at one of the study sites. A semistructured interview guide was used to conduct the interviews. Open ended questions were used to generate answers and these were probed until a full-understanding accomplished. The interviews were conducted in English and Twi and audiotaped with a digital voice recorder with the consent of participants. The interviews conducted in English were transcribed verbatim and those conducted in Twi were transcribed in English by the research assistants who understood the Twi language very well. The non-English transcripts were verified by the authors to further ensure the right content was reported. Each interview lasted between 30 and 60 minutes.

2.4. Data Quality Assurance. One facilitator and two observers who had worked with adolescents in health institutions were given a day's training. The training focused on the aim of the study, which is the process of conducting FGDs, the role of the facilitator and the observers in the FGD, and the topics to be discussed. Similarly, research assistants were taken through how to conduct IDIs. The interview guides for both the FGDs and the IDIs were pretested using three IDIs and one FGD in a different setting.

2.5. Data Analysis. The data were analyzed manually. The IDIs and FGDs were transcribed verbatim and processed using inductive thematic analysis [25]. Each of the tape recordings was separately transcribed by two independent research assistants and their scripts were compared. The transcriptions were compared and portions that differed significantly from each other were retranscribed by listening to those portions of the tape recording again. Thematic analysis was used to analyze the transcribed data and notes taken by the observer manually. First, the analysis of the data began with a search for similar ideas, thoughts, recurring words, and differences within the data. Second, codes were created manually based on the ideas, thoughts, and words. Similar and related codes were grouped to form themes and subthemes. The themes capture core issues discussed in relation to the overall research question. Third, as the analysis continued, related themes were clustered to form categories. The words representing the categories were written in the margin of the script where the theme or code was found and coloured. This was necessary to define and redefine logical connections between the themes for easy interpretation. Having developed the themes, the report was written verbatim, expressing the views and vivid thoughts of all the participants in the IDIs and FGDs.

2.6. Ethical Clearance. The study was approved by the Noguchi Memorial Institute for Medical Research Review 
Board (IRB 097/11-12), University of Ghana, Legon. Permission was also obtained from the Accra Metropolitan Director of Education, and the head teachers of the selected junior high schools. Each parent selected for the study signed a consent form before taking part in the study. The parents were told that they could withdraw from the study at any point when they felt they were no more interested. Confidentiality and privacy were assured throughout the study. Anonymity was maintained by not linking responses to individual participants. All the parents who consented to the FGDs or IDIs participated in the discussions or in-depth interviews to completion. Thus, none of the parents withdrew from the study at any given time.

\section{Results}

\subsection{Parents Discussing Sexuality Topics with Adolescents}

3.1.1. Sexuality Topics Parents Ever Discussed with Adolescents. Many of the parents reported that they talked about menstruation, peer pressure to engage in sex, premarital sex, and HIV/AIDS. These responses were age-related as all the parents involved in this study had children between the ages of 12 and 17 years. Other parents talked about body changes, personal hygiene, abstinence, the consequences of getting pregnant, abortion, and how to say "no" if somebody wanted to force them to have sex.

"I always hammer on premarital sex because I have two girls. I tell them that premarital sex is not safe because they could get pregnant. And if they become pregnant, they would face the consequences alone while the boy would continue his education. She, the girl would be drawn back in the number of years she would spend in school because she must stop the school and have the baby before going back to continue or she might not continue the school at all. Secondly, she could get sexually transmitted diseases which could affect her reproductive life in future." (a father who is an administrative officer, IDI)

"I talked to the children about the consequences of getting pregnant and abortion so that they will know exactly what to do and what not to do." (a father who is a mechanic, IDI)

Even though many of the parents said they did not find it difficult talking about any sexual topics with their adolescents, a mother admitted having problem talking to her daughter about sexuality issues.

"I find it difficult talking with my daughter about sexual intercourse and kissing because she would not like me to talk about it. Sometimes you would be watching TV with her and you would see her covering her face during such scenes or she would walk out of the room. Sometimes I call her to come back and ask her to sit down and watch. Then I would tell her that it was just a film and they are just showing what people have been doing. It is when you practice what you see that you will have problems." (a mother who is a data officer, IDI)

3.1.2. Gender and Age Disparities in Parent Discussion of Adolescent Sexuality. There were gender differences regarding communication among parents with their adolescents. The parents had diverse views about whether they should spend more time discussing sexual topics with boys or girls. Many of the parents would like to discuss more sexuality topics with their daughters because they perceived girls as more vulnerable than boys.

"...She is more gullible and easy to prey upon, so you have to give her the right information on sexual issues so that she can protect herself. Normally, it is the boys who are doing the chasing, so you must teach the girl to be assertive and how to say "no" to sex and she will be able to protect herself." (a mother in Osu Klottey, FGD)

"...When girls start developing changes in their bodies, the girl will think she is matured and not listen to you. If you are not careful and monitor her, she may go out to bring problems to you. Let's say she got herself pregnant, at least people know that your daughter is pregnant but if the boy goes out and gets somebody pregnant, nobody will see that your boy is pregnant." (a mother who is a teacher in Ablekuma South, IDI)

"...She is a girl and she is at the receiving end of any sexual action. She is the one who is going to suffer more be it her education, her life, or confidence level. It may affect her physically and psychologically. As for the boy, he can still go on with whatever he wants to do, even if he involves himself in sexual activity." (a father who is an administrative officer in Osu Klottey, IDI)

On the contrary, few mothers prefer to talk to the boys rather than the girls while other parents would talk to both sexes because they are all vulnerable.

"I will talk to the boy because in recent times we are having problems with boys being abused by men and this is now a worrying issue." (a mother in Ablekuma South, FGD)

"As a mother, I will start by talking with the two sexes together but as they grow, I will get the same gender that they can identify with to talk to them. This is because the boy has certain feelings that the mother doesn't know about but only hear of them. The boy and the father can talk as men and the mother can also talk with the girl." (a mother in Osu Klottey, FGD)

There were disagreements with the age at which parents should start discussing sexual issues with their children in the 
FGDs. Some of the parents believed that educating children about sexual issues should not be tied to age. Once the children understand what you are telling them, education can start.

"If a child asks a question, it is right for you to provide the right information to him/her and as he/she grows then you can be adding more information. We do not have to wait until a certain age before we start talking and if he/she comes with a question and you will say wait. No! We should provide the information as and when they need it." (a mother in Osu Klottey, FGD)

Another mother in the FGD narrated her experience with her 6-year-old son about sexual issues and why it is important to start talking to them at a young age.

\begin{abstract}
"My boy, before he turned 6 years of age, asked me why do boys urinate through the penis, but the girls do not? Does that mean that girls do not have penis? So, I must explain to him that the girls also urinate but through another place but not same as boys. You have to give an answer because they are inquisitive and observant." (a mother, Osu Klottey, FGD)
\end{abstract}

Other parents were of the view that education on sexual topics should be age appropriate. Some of the parents would like to start talking to their children at the age of 10 years because there would be physical changes in their bodies at this time. Other parents would like to start talking to their children at 9 years because some of the girls may start having their period at this age.

"I would like to start talking to my children about sex when they are 10 years because at this time there are physical changes in their bodies which they will notice so whatever you tell them they will understand." (a father who is a mechanic in Ablekuma South, FGD)

"I will like to start talking about sex with my child when my child is 9 years because these days some girls start having their period by this age. The hormones are working in them, so they are developing fast. When you see some of the adolescents you will think they are grownups and men usual approach them. So, when they are educated at this age they will know what to do in any situation." (a mother who is a teacher at Osu Klottey, FGD)

"Parents should start talking to their children as early as 6 years because nowadays children are broad minded. Things that you think they do not know they have already heard or seen them somewhere and they will ask you questions. As soon as they start asking you those questions you must start talking to them about sex." (a mother who is a trader in Osu Klottey, FGD)

3.1.3. Timing for Discussion of Adolescent Sexuality. Parents started talking to their adolescents about sexuality topics on different occasions. Some parents talked to their children when they watched an indecent television (TV) scene or indecent dressing on their way out with the children or used other peers' experiences as the basis to talk to their children.

\begin{abstract}
"When I am going out with the children and we see dresses young girls wear, such as short skirts and dresses that expose their cleavage (space between her breasts), I use such things to start talking to them and tell them that wearing such dresses expose you to harm. Some men may take advantage of what you are wearing and lure you into sexual activity and that will result in all manner of consequences. Other times when we are watching films, for example African movies and a romantic scene appeared, I use that as an opportunity to start talking to them about sexual matters." (a father who is a trader, IDI).

"Maybe something has happened to a family member and we are talking about it, I use such a channel to start talking with her. For example, I have a cousin who was about 16 years old and gave birth. Through that she could not continue with her schooling but the boy she had the baby with is still in school. That means that her future is curtailed but the boy will continue with schooling." (a mother who is a teacher, IDI).
\end{abstract}

3.1.4. Reasons for Parents' Discussion on Adolescent Sexuality. Parents from both the IDIs and FGDs confirmed discussing sexual topics with their adolescent children. However, there was no general agreement among the parents for the reasons of discussing sexual topics with their adolescents. The most important reason for discussing sexual topics with adolescents was to prevent them from engagement in early sexual activity.

"I talked about sexual issues with my daughter so that she would not be forced into sexual activity which would bring her problems. When girls associate with their friends, they try to learn bad things from their friends so you the parent must educate your child against such matters." (a mother who is a teacher, IDI)

"I noticed that at the age of 10 years, my daughter was developing some reproductive features, so I told her when she sees them it means that she is growing up. I told her that those features are not there for nothing. They are there for a purpose; when the time comes she will use them for the purpose. I talked to her because I think she needs the information. Despite her age if she knows that there are some consequences in certain acts like sex, she will be careful." (a father who is an administrative officer, IDI) 


\subsection{Parental Knowledge and Comfort Discussing Adolescent Sexuality}

3.2.1. Sources of Parental Knowledge about Adolescent Sexuality. Parental knowledge about adolescent sexuality issues is important to ensure that adolescents get the facts right. Various strategies were used by parents to improve their knowledge on adolescent sexuality issues. Some parents in the FGD mentioned that they sourced knowledge on adolescent sexuality from reading books on such topics. Others reported using programmes they watched on television to educate their adolescents on sexuality issues. Others also used family members and friends as resource persons to educate their adolescent children.

"I read books on adolescents' sexuality. Sometimes, if I feel I cannot talk about a topic, I ask my friend to help me to educate my child on it." (a mother who is a teacher, IDI)

"There is enough information on the television we watch, like HIV/AIDS so I call my daughter to come and watch and whatever advice I have I give her. Moreover, I work at the maternity department of a hospital and that has helped me to learn about what happens to young girls. Subsequently I advised her on situations I have seen at the hospital. Young girls come to the maternity department and I see them until they deliver. I see the problems they face, from start to the end." (a mother who is a record officer, IDI)

3.2.2. Parents' Comfort Talking about Adolescent Sexuality Topics. During the IDIs, parents expressed diverse feelings about their comfort talking to their children about sexual topics. While many of the parents said they felt comfortable talking to their adolescents about sexual topics, some did not.

"I feel very comfortable when talking about sexual issues with my daughter and my friends' children because I have been trained on adolescent sexuality." (a mother who is a nurse, IDI)

"I feel comfortable talking about any sexual topics with my children because I have four girls and I started with the most senior one and gradually the younger ones have also reached adolescence, so it made it very easy to talk to them about such issues as I have done so on several occasions." (a father who is a mechanic, IDI)

"I don't feel comfortable because sometimes I think they may ask me questions that need to be answered and I may not have the answers to give them. I also think that if you give them too much information, adventurous as children are, they may want to try whatever you told them, for example, condom, when they see what it is they may like to try it." (a father who is an administrative officer, IDI)

\subsection{Challenges and Strategies to Improve Parent Communica- tion on Adolescent Sexuality}

3.3.1. Challenges to Parent Communication on Adolescent Sexuality. There was no agreement among the parents on challenges or difficulties they faced talking to their children about sexuality. Some parents opined that they have difficulties talking to their children about sexuality topics. Parents have problems with timing of the talk, terminologies they could not explain to the children, and health implications of certain issues like menstruation.

"The difficulties I faced talking about sexual topics with my children are: the appropriate time to provide the education. ii. There are also some terminologies that I am not able to provide an appropriate explanation for the children to understand me. iii. There are some health implications such as having menses which I could not explain e.g. why some girls have regular menses while others have irregular? I don't know whether that is normal or not. Why some girls have their menses early and others late. For instance, some girls start their menses at 10 years but others at 15 years of age." (a father who is an administrator in Ablekuma South, FGD)

Other parents were worried because their children were not open to what they are telling them.

"Sometimes the children are not open to what you are saying to them. They will not like to listen to what you are saying. And if you force him/her, he/she will allow you to talk and after that he/she will ask you 'have you finished?' and he/she gets up and goes, that means he/she is not interested in what you told him/ her." (a mother who is a teacher in Ablekuma South, FGD)

Some parents gave reasons why their parents did not educate them on sexuality topics.

"To be honest, I was not given any education on sex. You are even scared to go and ask questions on such things. My parents didn't educate me because it might be that they were themselves not educated by their parents and hardly had any exposure." (a father in Osu Klottey, FGD)

"My parents never talked to me about sexual issues. I don't know whether or not they were feeling shy to talk to me about such issues." (a father in Ablekuma South, FGD)

"My parents didn't talk to me may be because my father was a pastor and could not tell me anything on sexuality." (a mother, Osu Klottey, FGD)

3.3.2. Strategies to Improve Parent Communication on Adolescent Sexuality. Many of the parents in the study believed that to improve communication between parents and adolescents, 
the former needs to start talking with their children at an early age because after a certain stage, it would be difficult to start talking to them. Other parents believed parents should have time with their children and talk with them regularly.

\begin{abstract}
"We should start talking to our children early and make them our friends because if the children grow up to a certain stage it will be difficult to start talking to them about sexual issues. But if we are friends to them since childhood and they have confidence in us and confide in us, it will be easy for us to talk to them even when they are adolescents." (a mother in Osu Klottey, FGD)

"Parents should have time to talk with their children, listen to them and answer their questions because if the children know that when they come to you, you will give them the right information even if they are not your friend they will come to you." (a mother in Osu Klottey, FGD)
\end{abstract}

The parents also identified closeness to children, reading to acquire more knowledge on adolescent sexuality, and provision of educational programmes on adolescents' sexuality on television and radio to educate parents and help them discuss sexual topics with their children.

"I have to read more and have more knowledge about sexual issues to talk with my children. There should be an educational programme on adolescent sexuality on television and radio to educate parents. You must get closer to your child and find out what he/she is doing at a time, monitor him/her and where he/she goes, know his/her friends and take interest in him/her. Once he/she knows that you are interested in him/her, she can confine in you and tell you his/her problem then you can talk to him/her often about sexual issues." (a mother who is a record officer, IDI)

3.3.3. Informal and Formal Sexuality Education. Parents expressed different opinions about the importance of informal and formal sex education as a strategy to improve parents ability to communicate effectively with adolescents on sexuality topics. Almost all the parents agreed that it would have been easier for them to communicate with their children on sexuality topics if they had received some form of education on these issues. Some parents mentioned that they received some talks on sexuality while they were adolescent, but it was only precautionary and to instil fear in you to avoid sex.

"I had some education, but it was precautionary. If you go and sleep with a girl she will get pregnant and they will come and arrest you. Such was the education." (a father who is an administrator, IDI)

"My mother never educated me on sex. She will not tell you that if you have sex you will be get pregnant. She will tell you if a man touches you, you will be pregnant, so I had that in my mind so whenever a boy approaches me I will ask him not to touch me because I do not want to be pregnant. I do not want my mother to see that I am pregnant." (a mother who is a record officer, IDI)

Parents believed that informal education from their parents will have enabled them to communicate with their adolescent children on sexuality topics better than what they are currently doing.

"If I had been educated when young I would have improved on what I am telling my children now because I would have gained more knowledge and experience than I have. Even the system we have now, you are bit restricted as what to educate our kids because you are not sure about what you are going to tell them. In effect you are reluctant when you want to give certain information to the children." (a father, Ablekuma South, FGD)

"It would have been far easier because I have the knowledge but how to impact the knowledge to my children is the problem. Probably, if my parents had talked to me I could have used the experience I had from them to talk with my child." (a mother, Ablekuma South, FGD)

"Yes, it would have contributed a lot. You know parents are the first teachers and before I grew up if I were to have some information on sexuality, wherever I go with a little top up will ameliorate what I have learnt. I would have had the understanding very well. So, when parents educate their children before they grow up it will help very much." (a father and an administrative officer, IDI)

Parents were asked if they thought formal training of parents on adolescent sexuality would help them talk to their children about the subject. Many of them were of the view that if parents were trained on adolescents' sexual issues, it would help them to know the appropriate ways to talk to their children about their sexuality.

"Training of parents will help because you see, education on adolescent sexuality is a sensitive topic which requires some formal training. You must find the appropriate time, put the message into appropriate language and the children should be in a right mood to receive the message. For that matter, parents need to be taught how to give the education." (a father who is an administrator, IDI)

"...Some parents have no knowledge about sexual issues or how to go about it. Therefore, if parents are trained, they will have the knowledge to educate their children and their children will, in 
turn educate their own children in future and they will be better than the present generation. I told my sister that "something" like blood is coming from my vagina when I had my first menses and she told my mother. When she told my mother about my experience, my mother said to me 'that is what we call 'period', don't you know, and I said I didn't. And she said that is what when a man calls you and you go you will become pregnant'. So, how will a man call me, and I will go'. You are afraid to go." (a mother, who is a record officer, IDI)

Parents expressed different opinions when they were asked about the impact of sex education on adolescent engagement in premarital sex. Most of the parents posited that adolescent sex education would not lead to premarital sex. However, other parents thought it could lead to premarital sex.

"Yes, because if you educate adolescents, out of
curiosity, they would like to find out whether
whatever you have told them is practicable or
works depending upon the sort of groups they find
themselves." (a mother, Ablekuma, FGD)

"No, educating them puts fear in them. Educating them will prevent them from indulging in early sexual activities, leading to a healthy sexual life now and in the future. But if we do not educate them now, when they grow up, they would become ignorant about a lot of things and they may find themselves wanting." (a father, Osu Klottey, FGD)

"I think it depends on how you go about the education. Because some of the adolescents are adventurous, and when you talk to them about sex, they will really want to find out what it is about. So, it is better we educate them, but we should let them know the dangers associated with indulging in sexual activity. Most of the adolescents indulge in sex because they may learn about it at school, but the teacher probably did not educate them about the dangers associated with indulging in sex. So, they want to experience it." (a mother, Osu Klottey, FGD)

\section{Discussion}

4.1. Parents Discussing Sexuality Topics with Adolescents. This study focused on parents' experiences discussing sexuality topics with their adolescent children. In agreement with previous studies in Ghana $[15,26]$ and in sub-Saharan Africa [22], parents reported talking to their adolescent children on various sexuality topics. Regarding sexual topics discussed with the adolescents, the parents reported that they discussed menstruation, peer pressure, premarital sex, HIV/AIDS, boy/girl relationships, personal hygiene, pregnancy, abstinence, sexually transmitted infections (STIs), abortion, and how to say "no" to forced sex. Previous studies have reported similar range of sexual topics discussed by parents with their children, such as physical development, abstinence, unplanned pregnancy, HIV/AIDS, sex/intercourse, STIs, and safe sex [5, 22]. Among the topics discussed, abstinence was a major topic. Parents were particularly concerned with their female adolescents' indulgence in premarital sex since the outcomes of such actions are normally disastrous. It is important to note that these discussions tend to be precautionary as documented in previous studies from subSaharan Africa in which sexual discussions were authoritative and characterized by vague warning [22]. In this study, parents did not mention that they talked about contraceptive and condom use with their adolescents. This finding is consistent with previous studies in Tanzania and Nigeria that reported these topics as the least talked about by parents with their children during sexual discussions [27, 28]. On the contrary, a study in the United States indicated that parents often discuss issues such as condom use and protection with their adolescents [29]. Parents in Nigeria did not talk about contraceptives and condom use with their adolescents because they believed that such discussions would promote promiscuity [28]. Unacceptable opinions originating from cultural and religious beliefs may also underpin the low communication on contraceptive and condom use in the African setting compared to the United States and other developed countries.

The findings from this study also indicate that parents talk to their adolescents for various reasons; the most important is to prevent adolescent engagement in premarital sex. This supports earlier studies in the United States which observed that parent-adolescent communication about sex has been associated with delayed start of early sexual intercourse [21]. The benefits of sex education amassed by adolescents may be dependent on several factors, including timing of discussions as well as the nature of the discussion. While discussion of sexuality with adolescents has been a controversial issue, parents recounted that they started talking to their children on different occasions and on various topics. Many of them reported that they initiated discussions about sexuality topics with their adolescents while viewing television that showed romantic scenes. These views expressed by the Ghanaian parents is in consonance with previous studies of Caucasian, Latino-American, African-American, African, and Asian parents particularly mothers who take advantage of events like watching television to talk about sex-related topics with their children [5]. It is worthy of note that parents also took advantage of life situations as a case study for sex education, especially in instances when an adolescent's family member gets pregnant. They used such happenings as an opportunity to initiate discussion on safer and more protective sexual behaviours so that younger siblings/children can identify problems and solutions as they watch the consequences that befell victims of early sexual activities and do not repeat the same mistakes.

4.2. Gender and Age Disparities in Parent Discussion of Adolescent Sexuality. Although parents have the responsibility of discussing sexuality topics with both sexes, higher priority is given to educating their daughters. This finding agrees 
with prior studies that more mothers would like to talk with their daughters than with their sons about sex-related topics $[4,22]$. Parents may be more concerned with the welfare of their daughters rather than sons as they would not like their daughters to indulge in early sex. This may be because parents are protective of their daughters as in any event, such as pregnancy, the daughter bears the greatest consequences. Regarding the suitable age at which parents could instigate conversation on sex-related discussions with their adolescents, parents wanted to start talking to their children about sexual topics as early as 10 years. This age estimate is identical to what parents in the United States and Greece opined; that is, their children should be educated about sexuality topics during the primary school years (between 10 and 12 years) $[5,30]$. Among the parents who indicated a desire to educate children on sexuality topics at 10 years or younger (during the preadolescence stage), their reason was the desire to provide their children with the right information before they become sexually active. This is because it would be easier to start talking to children when they are preadolescent since they are more likely to listen and adopt it than when they grow older. If parents do not talk to their children about sex, it will mean that they will not have control over what their children learn about sex. Children are generally exposed to sexual issues from peers, sexual images, and sexual content in magazines, television, radio, and movies. Since parents cannot prevent adolescents from accessing sexual information, no matter how hard they try, they must provide them with education to make the right sexual decisions.

\subsection{Parental Knowledge and Comfort Discussing Adolescent} Sexuality Topics. Parents' knowledge about sexual topics motivates them to discuss sexuality topics with their adolescents. The more knowledgeable a parent is about sexuality topics, the more comfortable he or she feels about discussing such topics with his/her adolescent. A study in Bangladesh reported lack of knowledge among parents on basic understanding of adolescent reproductive and sexual health issues [31]. In the case of Ghana, parents showed varied levels of knowledge on adolescent sexual topics and this has been reported elsewhere [26]. A study among Australian parents also confirmed that parents felt generally knowledgeable about educating their children about sexuality [32]. In Ghana, mothers and aunties are mostly the main educators of children about sexuality issues. Evidence in an earlier study in Ghana indicated that the mother is the main resource person on sexual communication with adolescents [15]. Mothers may view the education of adolescents as their responsibility and, therefore, make more effort to acquire knowledge to enable them to discuss these issues with their adolescents. Fathers may not be so interested in adolescent sexuality topics because they may think that it is the mothers' duty. Some fathers may also genuinely not have the knowledge about sexual topics and need to be motivated to learn more about sexual topics in order to educate their children about such issues.

Although these parents generally reported feeling knowledgeable, they still resort to improve their knowledge by reading books on sexual topics. Other parents also reported buying books for their children to read themselves. Parents watching TV programmes and advice from friends were other sources of knowledge for parents about adolescent sexual and reproductive health issues. A similar finding was reported in a study in the United States in which parents used available resources such as books on sexuality topics (that is, for themselves and their children), TV programmes, and advice from parents and friends to improve their knowledge and ability to communicate with their children on adolescent sexuality issues [5]. Parents reading books on sexual topics and buying books for their children to read suggest that they have realized the need for them and their children to have more information on sexual and reproductive health issues. Unfortunately, the purchasing of these books for their children to read to acquire information on sexuality issues may not be sufficient for some children who might have difficulty in understanding what they read. Such children may therefore need parental support. Beyond what may be read in the books, parents may need to adapt and interpret knowledge in relation to the context that their adolescent lives in. However, parental use of other parents as resource persons in educating their adolescents about sexual topics is commendable.

Parental fear of being unable to answer sex-related questions posed by their adolescents emerged during the in-depth interviews as a reason for discomfort in discussing sexual topics with adolescents. In a study in Ethiopia, fathers did not discuss sex and menses issues with their children because it made them uncomfortable, as it was not traditionally accepted [33]. Again, in the United States, Wilson et al. [5] had earlier identified parental inability to handle questions posed by their children due to lack of technical knowledge on sexual topics. In Ethiopia, it was mentioned that even though parents valued their knowledge about the adolescent sexuality, this was not accepted by their children. In other words, they did not know what to do in those circumstances [33]. Therefore, having knowledge alone may not be enough and it must be coupled with communication and comfort enhancement strategies. Evidence-based programmes aimed at improving parental knowledge on adolescent sexuality must include modules to enhance parental comfort so as to improve frequency of such communications with adolescent children.

\subsection{Challenges and Strategies to Improve Parent Communi-} cation on Adolescent Sexuality. Many parents face difficulties while discussing sexuality topics with their adolescents. This is because either the parents have problems when talking to their children or the children are not prepared to listen to the parents. Some parents in the in-depth interviews confirmed that they had difficulties when talking about sexuality issues with their adolescents. In the United States, parents reported that they experienced some types of difficulty such as unease about physical development and embarrassment when discussing sexual issues with their children [34]. Another parent had difficulty with technical aspects of sexuality such as the terminologies which he could not explain to his/her children to understand him. In the United States, Latino parents had difficulties when talking about technical aspects of 
sexuality, including contraceptives as they require specialized knowledge [35]. Sexuality is a specialized area which needs expert knowledge; thus some parents find it difficult to talk about sexuality issues. The need for expert knowledge, therefore, is paramount for parents to communicate better. Nonetheless, parents can explore sexuality topics with their children and learn together. Another possible reason why parents had difficulties talking to their children could be the late start of sex education. As the children grew up parents felt uncomfortable to discuss sexuality issues with their adolescents. For such discussions to take place, a good parent-child relationship needs to be built with the child at a younger age. This would encourage parent-adolescent communication when the children become adolescents.

4.5. Informal and Formal Sexuality Education. Many of the parents complained that they were not educated on sexuality when they were young, and this has made it difficult for them to educate their children now. This is in keeping with a 2010 study in the United States which reported that parents complained about their inability to talk to their own children about sex because they were not educated by their parents [5]. In Kenya, Mbugua also observed that among mothers who had no sex education from parents, providing sex education to their own daughters became difficult [4]. Parents believed that if they had been educated on sexual issues when they were young, it would have been easier for them to educate their own children.

Some parents also mentioned that they were educated on sexuality, but it was just precautionary. Other parents said that they never had any education on sex from their parents but received metaphoric caution against sex. In a study in Nigeria, parents deliberately misinformed their daughters about the realities of sex in order to discourage them from being interested in sexual matters and put fear into them against premarital sex [28]. This trend of authoritative, vague warning rather than direct open discussion is a common theme as documented in a review of studies of parentadolescent communication about sexuality in sub-Saharan Africa [22]. There should be mutual consent between parents and adolescents concerning sexuality discussions such that a dialogue may ensue rather than it being a unidirectional communication. It is significant for parents to talk with their adolescent children to break the tradition of silence of talking about sexuality.

It was evident from this study that just parental knowledge on adolescent sexuality topics may not be enough. Some parents had the knowledge, but how to communicate the information to their adolescents was a challenge since this was considered as a sensitive issue; hence they would prefer not to talk about it. Many of the parents in both the FGDs and IDIs asserted that if parents receive structured training on communication about adolescent sexuality, it would enable them to talk with their adolescents about sexuality. Other researchers have also reported similar views by parents in different countries $[4,5,34,35]$. Training parents to talk to their children about sexuality has other benefits like improving their knowledge of sexuality topics, confidence, ability, and comfort to discuss such sensitive topics with their children [26].

4.6. Limitations of the Study. This study was conducted among parents in urban settings; hence the findings cannot be generalized to parents in rural setting. However, it is important to note that these parents were originally not from the city and may have migrated from rural settlements into their present urban locations. Hence, it is possible that parents in rural settings can identify with most of the views expressed by these parents in the urban setting. Another limitation to this study is the lack of information on the cultural and religious barriers to sex education in an urban context. This limitation is the focus of another manuscript under revision elsewhere. It is likely that the parents who were most likely to agree to take part in the study were parents who felt the most comfortable talking about sexuality, which may have affected the results. The diversity of ethnic groups represented by the parents is a strength to the current study which implored both FGDs and IDIs to express parents' experiences discussing adolescent sexuality topics in the Accra Metropolis.

\section{Conclusion}

It is important for parents to discuss sexual topics with adolescents to prevent exposure to early sex, pregnancy, and sexually transmitted diseases. Although girls are more vulnerable than boys, both sexes need education on sexuality, and it will be much easier for such an education to be effective if parents get closer to their children and start discussions about sexuality issues with them at a younger age. In a nut shell, parents may need some form of education to be able to handle challenges of sexuality discussions with adolescents.

\section{Abbreviations \\ IDI: In-depth interview \\ FGD: Focus group discussion.}

\section{Data Availability}

The data used to support the findings of this study are included within the article.

\section{Consent}

It is not applicable to this manuscript since this study does not include details, images, or videos related to individual participants.

\section{Disclosure}

The funding agency was not involved in the design of the study and data collection, analysis, and interpretation of the results. The views reflected in this manuscript are those of the authors and do not in any way reflect the views of the funding agency. 


\section{Conflicts of Interest}

The authors declare that they have no conflicts of interest.

\section{Authors' Contributions}

Elizabeth AKu Baku and Richard M. K. Adanu conceived the study. Elizabeth AKu Baku and Isaac Agbemafle performed the data analysis. Elizabeth AKu Baku, Isaac Agbemafle, and Agnes Millicent Kotoh drafted the script. Isaac Agbemafle reviewed the scripts and made the necessary corrections. All authors read and approved the final manuscript.

\section{Acknowledgments}

The research was financed by the Ghana Education Trust Fund (GETFUND). We are grateful to all the parents who dedicated their time and resources to the in-depth interviews and focus group discussions.

\section{Supplementary Materials}

Interview guide for IDI and FGD. (Supplementary Materials)

\section{References}

[1] J. J. Arnett, "Conceptions of the transition to adulthood among emerging adults in American ethnic groups," New Directions for Child and Adolescent Development, vol. 2003, no. 100, pp. 63-75, 2003.

[2] M. Kirkman, D. A. Rosenthal, and S. S. Feldman, "Talking to a tiger: fathers reveal their difficulties in communicating about sexuality with adolescents," New Directions for Child and Adolescent Development, no. 97, pp. 57-74, 2002.

[3] G. Sedgh and R. Hussain, "Reasons for contraceptive nonuse among women having unmet need for contraception in developing countries," Studies in Family Planning, vol. 45, no. 2, pp. 151-169, 2014.

[4] N. Mbugua, "Factors inhibiting educated mothers in Kenya from giving meaningful sex-education to their daughters," Social Science \& Medicine, vol. 64, no. 5, pp. 1079-1089, 2007.

[5] E. K. Wilson, B. T. Dalberth, H. P. Koo, and J. C. Gard, "Parents' perspectives on talking to preteenage children about sex," Perspectives on Sexual and Reproductive Health, vol. 42, no. 1, pp. 56-63, 2010.

[6] C. Beyers, "Sexuality education in south africa: a sociocultural perspective," Acta Academica, vol. 43, no. 3, pp. 192-209, 2011.

[7] Ghana Statistical Service, Ghana Demographic and Health Survey (GDHS), Ghana, 2008.

[8] A. M. Moore, A. E. Biddlecom, and E. M. Zulu, "Prevalence and meanings of exchange of money or gifts for sex in unmarried adolescent sexual relationships in sub-Saharan Africa," African Journal of Reproductive Health, vol. 11, no. 3, pp. 44-61, 2007.

[9] Report FHDA: Adolescent Health, Ghana Health Service, Accra, Ghana, 2016.

[10] Demographic and Health Survey: Teenage pregnancy in Nigeria: Facts and Truth, Ministry of Health, Nigeria, 2013.

[11] Survey KDaH: $18 \%$ The rate of teenage pregnancy and motherhood in Kenya, Ministry of Health, Kenya, 2014.
[12] B. Masilela, Teen Mothers contribute $13 \%$ to child birth in SA/IOL News, Africa News Agency, South Africa, 2017.

[13] E. Baku, R. Adanu, and P. Adatara, "Socio-cultural factors affecting parent-adolescent communication on sexuality in the Accra Metropolis, Ghana," NUMID HORIZON, International Journal of Nursing and Midwifery, vol. 1, no. 2, pp. 1-10, 2017.

[14] S. A. Owusu, "Cultural and religious impediments against sex education," Feature Article, Wednesday, 5th December 2012, https://www.ghanaweb.com/GhanaHomePage/NewsArchive/ Cultural-and-Religious-Impediments-against-Sex-Education258360.

[15] A. Kumi-Kyereme, K. Awusabo-Asare, A. Biddlecom, and A. Tanle, "Influence of social connectedness, communication and monitoring on adolescent sexual activity in Ghana," African Journal of Reproductive Health, vol. 11, no. 3, pp. 133-149, 2007.

[16] V. Brocato and A. Dwamena-Aboagye, Violence against Women and HIV/AIDS, Y. Amissah, Ed., The Ark Foundation, Achimota, Ghana, 2007.

[17] M. Beasley, A. Valerio, and D. Bundy, A Sourcebook of HIV/AIDS Prevention Programs, vol. 2, Education Sector-Wide Approaches, World Bank, Washington, DC, USA, 2008.

[18] K. Awusabo-Asare, M. Stillman, S. Koegh, D. T. Doku, A. Kumi-Kyereme, and K. Esia-Donkor, From Paper to Practice: Sexuality Education Policies and their Implementation in Ghana, Guttmacher Institute, New York, 2017, https://www.guttmacher .org/report/sexuality-education-ghana.

[19] J. Anarfi and A. Owusu, "The making of sexual being in ghana: the state, religion and influence of society as agents of sexual socialization," Sexuality and Culture, vol. 15, pp. 1-18, 2011.

[20] J. Osafo, E. Asampong, and C. Ahiedeke, "Perception of parents on how religion influences adolescent sexual behaviours in two communities: implications for hiv and aids," Journal of Religion and Health, vol. 53, no. 4, pp. 959-971, 2014.

[21] J. D. Hanson, T. R. McMahon, E. R. Griese, and D. B. Kenyon, "Understanding gender roles in teen pregnancy prevention among american indian youth," American Journal of Health Behavior, vol. 38, no. 6, pp. 807-815, 2014.

[22] S. Bastien, A. Biddlecom, and W. Muhwezi, "A review of studies of parent-child communication about sexuality and HIV/AIDS in sub-Suharan Africa," Reproductive Health, vol. 8, no. 25, pp. $1-17,2011$.

[23] S. K. Henshaw, I. Adewole, S. Singh, A. Bankole, B. OyeAdeniran, and R. Hussain, "Views of adults on adolescent sexual and reproductive health: qualitative evidence from Ghana," Occasional Report, vol. 34, no. 1, pp. 40-50, 2008.

[24] M. Walsh and L. Wigens, Introduction to Research: Foundation in Nursing and Health Care, Nelson Thomas Ltd, Delta Place, UK, 2003.

[25] V. Braun and V. Clarke, "Using thematic analysis in psychology," Qualitative Research in Psychology, vol. 3, no. 2, pp. 77-101, 2006.

[26] E. A. Baku, I. Agbemafle, and R. M. K. Adanu, "Effects of parents training on parents' knowledge and attitudes about adolescent sexuality in Accra Metropolis, Ghana," Reproductive Health, vol. 14, no. 1, 2017.

[27] J. Wamoyi, A. Fenwick, M. Urassa, B. Zaba, and W. Stones, "Parent-child communication about sexual and reproductive health in rural Tanzania: implications for young people's sexual health interventions," Reproductive Health, vol. 7, pp. 6-23, 2010.

[28] C. O. Izugbara, "Home-based sexuality education: Nigerian parents discussing sex with their children," Youth and Society, vol. 39, no. 4, pp. 575-600, 2008. 
[29] E. I. Pluhar and P. Kuriloff, "What really matters in family communication about sexuality? a qualitative analysis of the effect and style among African American mothers and adolescent daughters," Sex Education, vol. 4, no. 3, pp. 3003-3321, 2004.

[30] A. Kakavoulis, "Family and sex education: a survey of parental attitudes," Sex Education, vol. 1, no. 2, pp. 163-174, 2001.

[31] U. Rob, T. Ghafur, I. Bhuiya, and M. N. Talukder, "Reproductive and sexual health education for adolescents in Bangladesh: Parents' view and opinion," International Quarterly of Community Health Education, vol. 25, no. 4, pp. 351-365, 2006.

[32] A. Morawska, A. Walsh, M. Grabski, and R. Fletcher, "Parental confidence and preferences for communicating with their child about sexuality," Sex Education: Sexuality, Society and Learning, vol. 15, no. 3, pp. 235-248, 2015.

[33] D. G. Yesus and M. Fantahun, "Assessing communication on sexual and reproductive health issues among high school students with their parents, Bullen, Woreda, Benishangul Gumuz Region, North West Ethiopia," Ethiopian Journal of Health Development, vol. 24, no. 2, pp. 89-95, 2010.

[34] P. Jerman and N. A. Constantine, "Demographic and psychological predictors of parent-adolescent communication about sex: a representative statewide analysis," Journal of Youth and Adolescence, vol. 39, no. 10, pp. 1164-1174, 2010.

[35] M. Raffaelli and L. L. Ontai, "'She's 16 years old and there's boys calling over to the house': An exploratory study of sexual socialization in Latino families," Culture, Health and Sexuality, vol. 3, no. 3, pp. 295-310, 2001. 


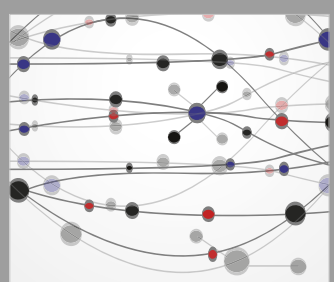

The Scientific World Journal
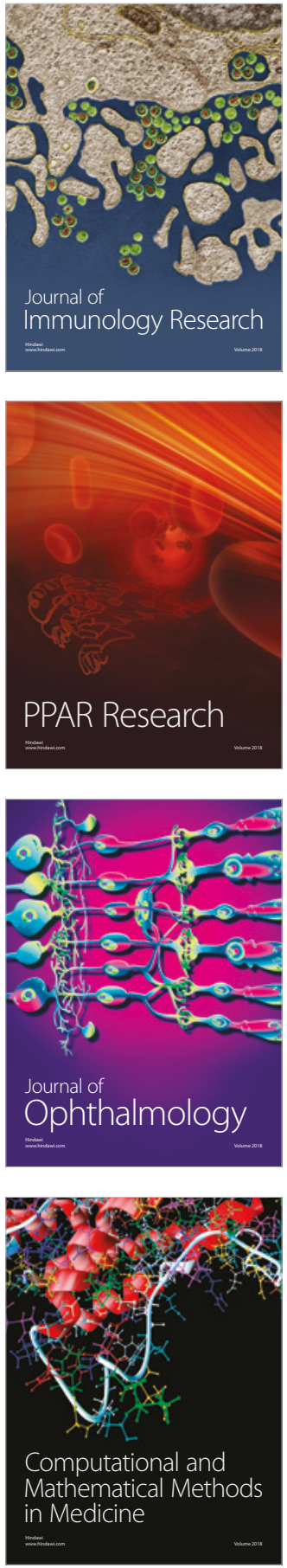

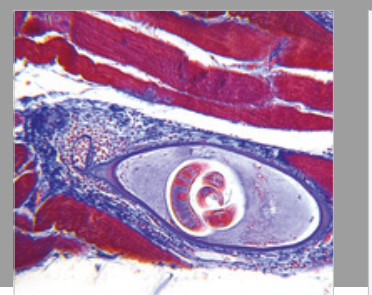

Gastroenterology Research and Practice

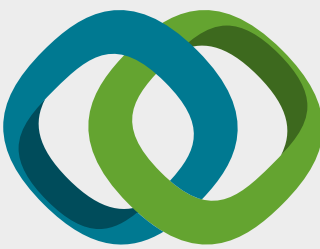

\section{Hindawi}

Submit your manuscripts at

www.hindawi.com
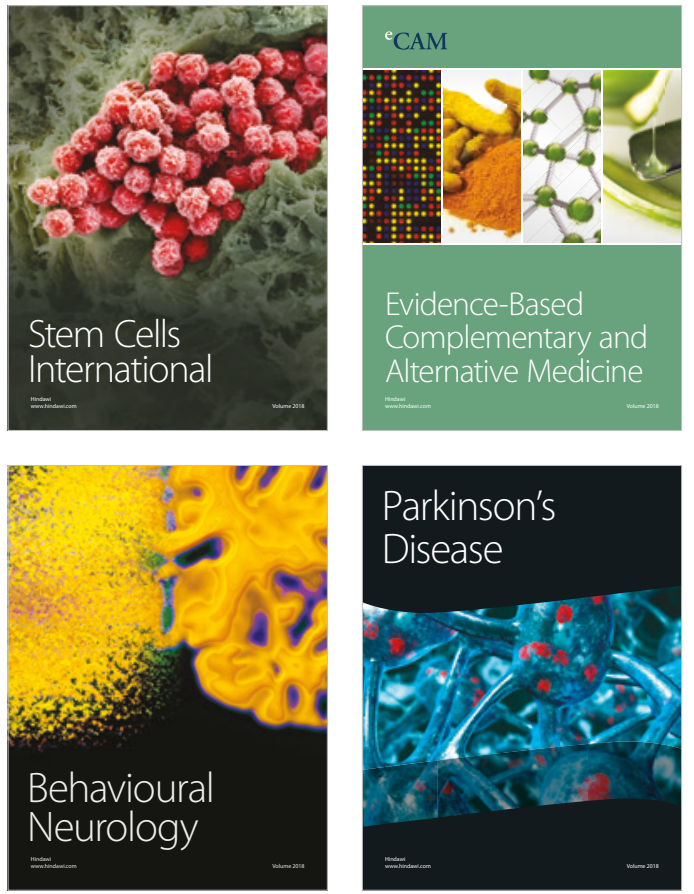

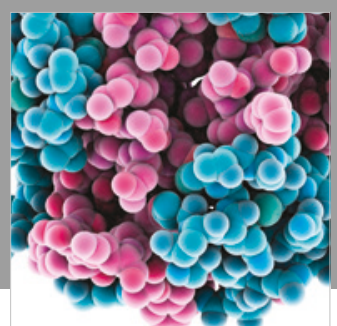

ournal of

Diabetes Research

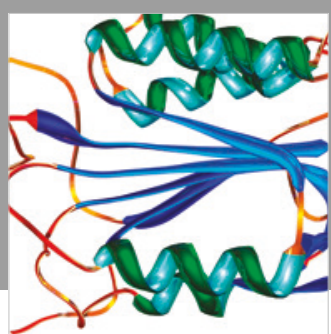

Disease Markers
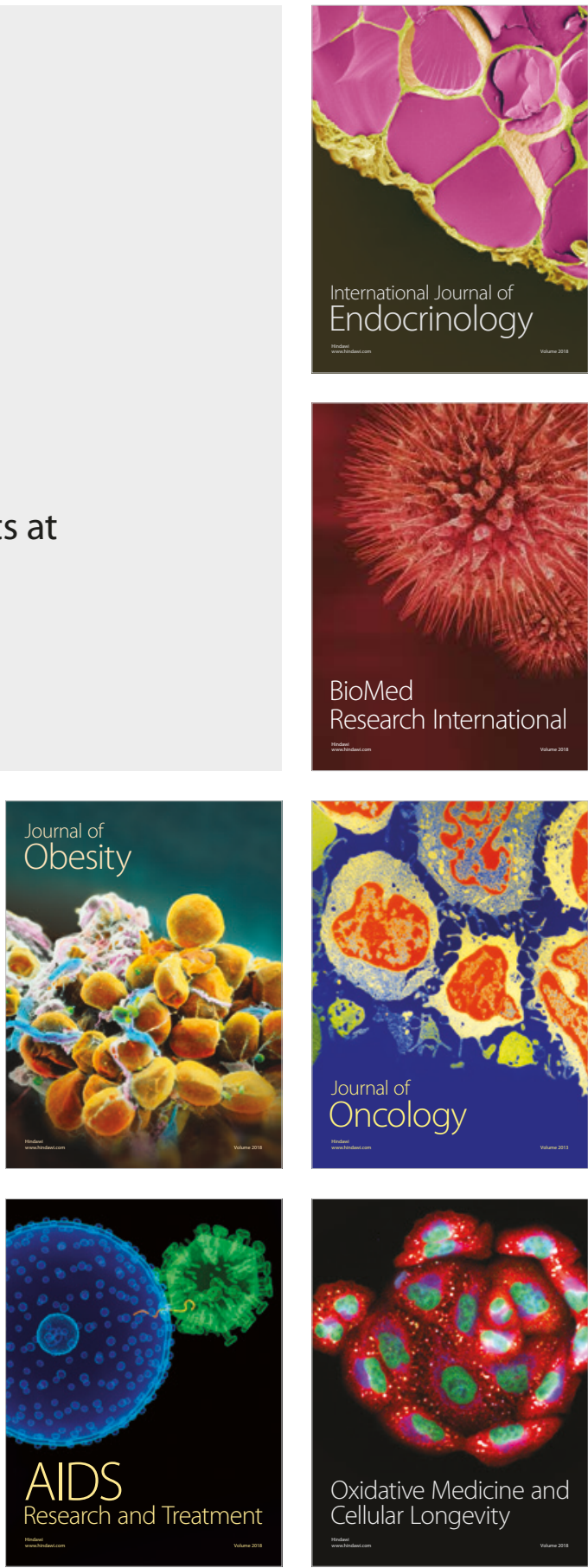